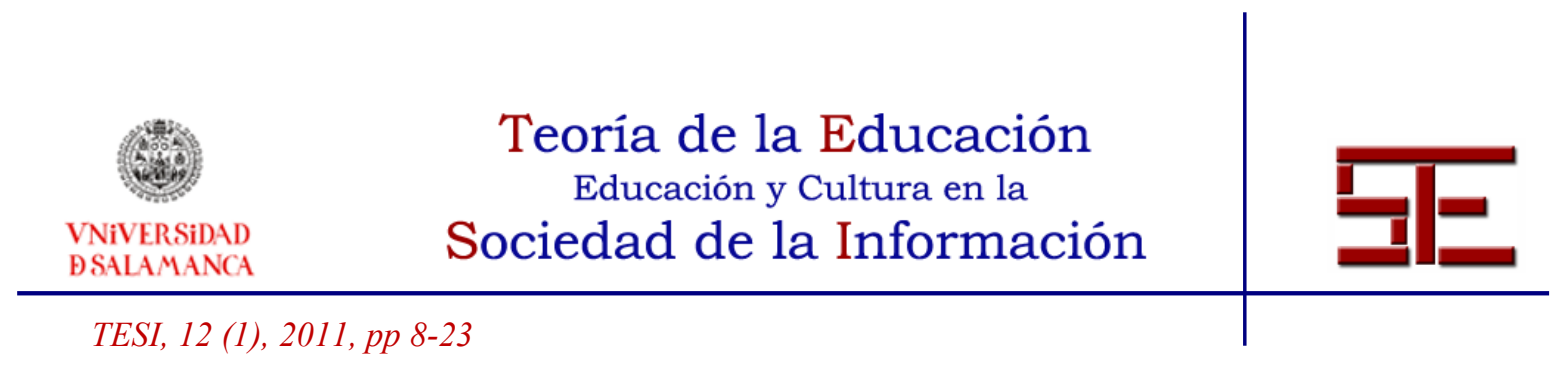

\title{
MUJERES E (INDUSTRIA) AUDIOVISUAL HOY: INVOLUCIÓN, EXPERIMENTACIÓN Y NUEVOS MODELOS NARRATIVOS
}

Resumen: Este artículo analiza las prácticas artísticas audiovisuales en el contexto actual. Describe, en primer lugar, el proceso de involución de las prácticas audiovisuales realizadas por mujeres artistas. Las mujeres no están presentes ni como productoras, ni realizadoras, ni como ejecutivas de la industria audiovisual de tal manera que inevitablemente se reconstruyen y refuerzan los estereotipos tradicionales de género. A continuación el artículo se aproxima a la práctica artística audiovisual feminista en la década de los 70 y 80 . Tomar la cámara se hizo absolutamente necesario no sólo para dar voz a muchas mujeres. Era necesario reinscribir los discursos ausentes y señalar un discurso crítico respecto a la representación cultural. Analiza, también, cómo estas prácticas a partir de la década de los 90 exploran nuevos modelos narrativos vinculados a las transformaciones de la subjetividad contemporánea, al tiempo que desarrollan su producción audiovisual en un "campo expandido" de exhibición. Por último, el artículo señala la relación de las prácticas feministas audiovisuales con el complejo territorio de la globalización y la sociedad de la información. La narración de la experiencia local ha encontrado en el audiovisual un medio privilegiado para señalar los problemas de la diferencia, la identidad, la raza y la etnicidad.

Palabras clave: Feminismo; género; industria audiovisual; estereotipos de género; involución.

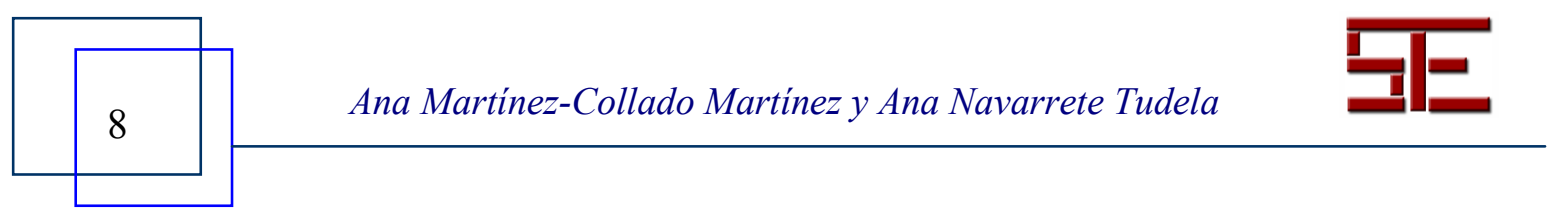




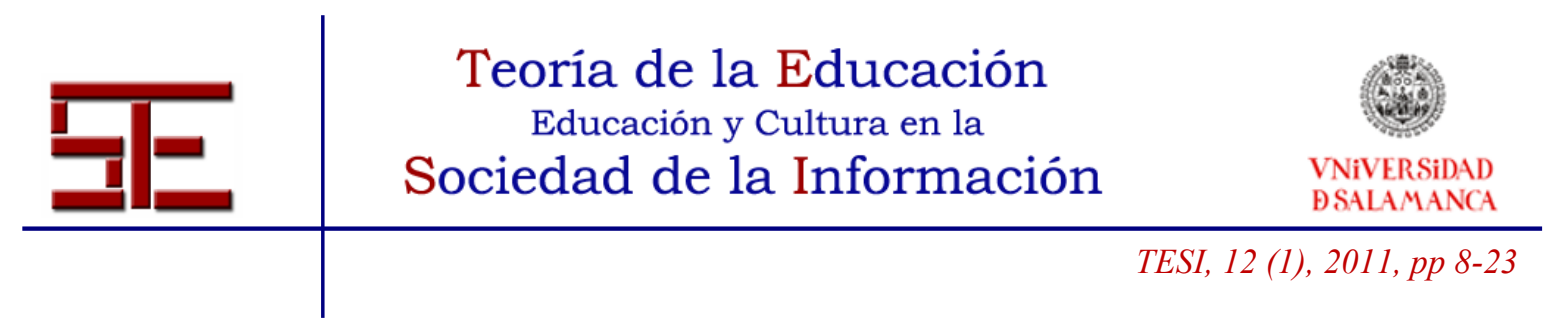

\section{WOMEN AND THE AUDIOVISUAL (INDUSTRY) TODAY: REGRESSION, EXPERIMENT AND NEW NARRATIVE MODELS}

Abstract: This article analyses audiovisual art in the contemporary context. Firstly it describes the current regression of the role of women artists' audiovisual practices. Women have little or no presence in the audiovisual industry as producers, filmmakers or executives, a condition that inevitably reconstitutes and reinforces traditional gender stereotypes. The article goes on to look at the feminist audiovisual practices of the nineteen seventies and eighties when women's filmmaking became an absolutely necessity, not only to give voice to women but also to inscribe discourses found to be absent from audiovisual practice and to generate critical discourses concerning the culture of representation.

The article also analyses how, since the nineties, such practices have explored new narrative models related to the transformation of contemporary subjectivity which have simultaneously extended audiovisual practice into an expanded field of dissemination Lastly, the article explores the relationship between feminist audiovisual practices and the complex territory of globalization and the information society and how the audiovisual narration of localized experiences have become a privileged medium for highlighting problems of difference, identity, race and ethnicity.

Key words: Feminism; gender; audiovisual industry; gender stereotypes; experiment.

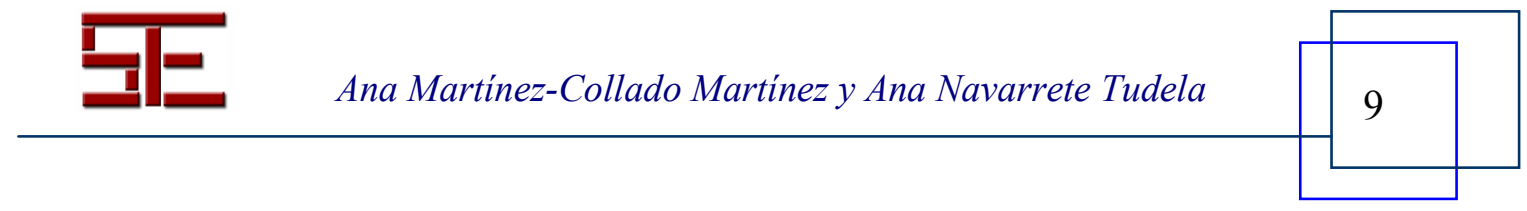




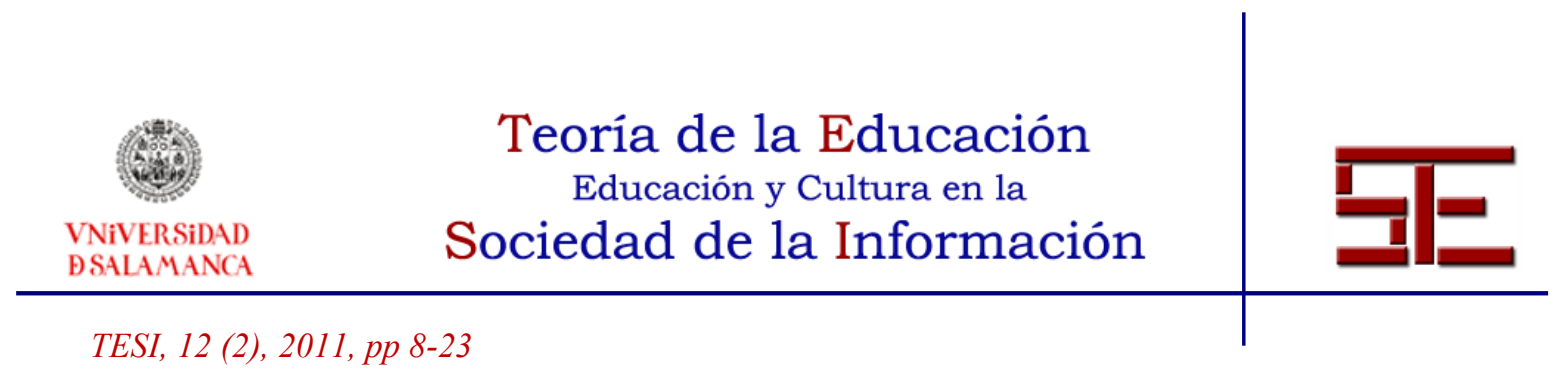

\title{
MUJERES E (INDUSTRIA) AUDIOVISUAL HOY: INVOLUCIÓN, EXPERIMENTACIÓN Y NUEVOS MODELOS NARRATIVOS
}

Fecha de recepción: 07/05/2011; fecha de aceptación: 18/007/2011; fecha de publicación: 27/07/2011

\author{
Ana Martínez-Collado Martínez \\ ana.martinez@uclm.es \\ Universidad de Castilla-La Mancha \\ Ana Navarrete Tudela \\ ana.navarrete@uclm.es \\ Universidad de Castilla-La Mancha
}

\section{EN RELACIÓN AL CONTEXTO AUDIOVISUAL EN ESPAÑA. INVOLUCIÓN COMO TENDENCIA ACTUAL}

\begin{abstract}
En un mundo ordenado por la desigualdad sexual, el placer de mirar se encuentra dividido entre activo/masculino y pasivo/femenino. La mirada masculina determinante proyecta sus fantasías sobre la figura femenina que se organiza de acuerdo con aquella. En su tradicional papel exhibicionista las mujeres son a la vez miradas y exhibidas (Mulvey, 1975) ${ }^{1}$.

Las representaciones son construcciones artificiales, (aparentemente inmutables), mediante las cuales aprehendemos el mundo: representaciones conceptuales tales como: imágenes, lenguaje o definiciones; que a la vez incluyen y construyen otras representaciones sociales como la raza y el género. Aunque estas construcciones suelen depender de un elemento material del mundo real, las representaciones siempre se postulan como "hechos" naturales y su engañosa plenitud oscurece nuestra aprehensión de la realidad (Wallis, 1984).
\end{abstract}

Las cifras de participación de las mujeres en la industria audiovisual en nuestro país son exiguas: actualmente solo el $9 \%$ de las películas que se dirigen están hechas por mujeres. En guion y producción sólo hay una participación femenina del 19\%, es alarmante la escasez de la presencia de la mujer en los puestos de decisión en los medios de comunicación. Y esto es igual para cualquier producción audiovisual: cine, televisión, documental o vídeo independiente. La igualdad en el medio audiovisual dista mucho de haberse conseguido. Algunos analistas hablan de una lenta evolución. No obstante podemos asegurar que tal evolución se ha estancado, incluso que estamos asistiendo a una involución en la situación de la mujer. En el caso de las artes plásticas la participación de las mujeres ha sido exigua, pero aún más en la industria audiovisual.

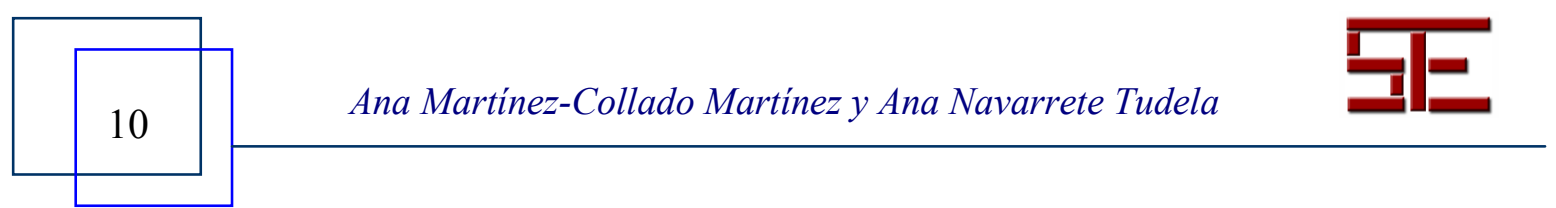




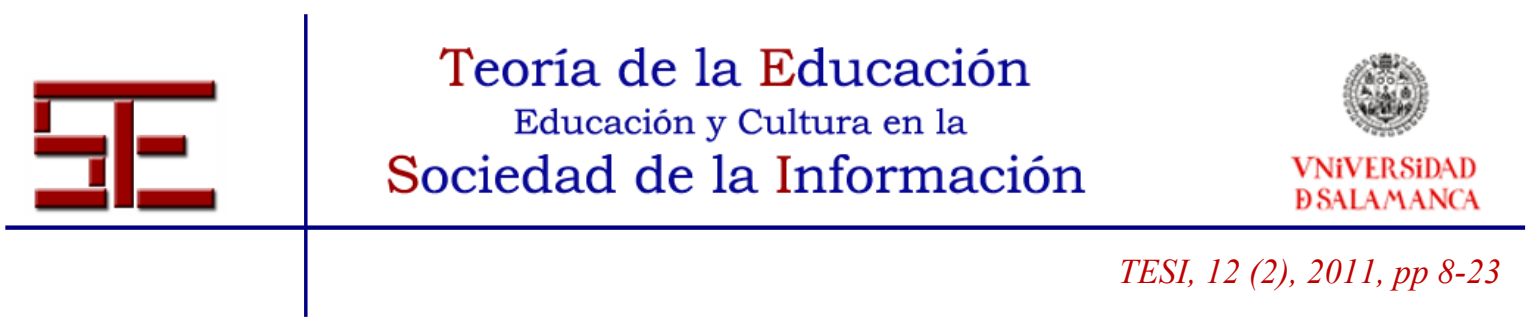

En el caso del cine español hasta los años 90 sólo se conocían 11 mujeres directoras de cine -destacan nombres como Ana Mariscal, que rodó 10 largometrajes al servicio del régimen o Margarita Aleixadre, que en los años 50 marchó a Cuba-. Durante la transición destacan nombres como Josefina Molina, Pilar Miró y Cecilia Bartolomé y algo más jóvenes a mediados de los 80: Pilar Távora, Ana Díez, Cristina Andreu, Isabel Mulá e Isabel Coixet ${ }^{2}$.

El boom llegó en los 90 con más de una treintena de directoras, aunque sólo significaron el $5 \%$ del total de directores surgidos en esta época, y en la mayoría de los casos gracias al decreto Miró y al trabajo ministerial de Carmen Alborch. Este cine es fundamentalmente ginecéntrico (en general, habla de la existencia femenina y la experiencia de ser mujer), no hay en toda esta generación de directoras ningún interés por reivindicar un discurso sexuado, de hecho, rechazan con contundencia que su obra se defina como "cine de mujeres", y mucho menos feminista. Este es un síntoma de cómo el patriarcado y su lógica de la igualdad está inscrito en nuestras subjetividades.

Además de que estas cifras ya eran desalentadoras, después de 1997 la presencia de las mujeres detrás de la cámara ha ido disminuyendo. Las consecuencias son nefastas: hay menos mujeres detrás de la cámara, hay menos protagonistas femeninas, hay menos preocupación por la vida de las mujeres.

Si las mujeres no están presentes ni como productoras, ni realizadoras, ni como ejecutivas de la industria audiovisual se produce un efecto inmediato en el tratamiento (o ausencia) de temas y enfoques de la mujer y se reconstruyen y refuerzan los estereotipos de género.

En el periodo que va desde mediados de los años 80 hasta la actualidad observamos como el discurso feminista no sólo se ha invisibilizado, sino que casi ha desaparecido como discurso y práctica política; o aun se ha domesticado. En Reacción: la guerra no declarada contra la mujer moderna (1991), Susan Faludi ya advertía de esta involución de los derechos de las mujeres; involución que queda claramente inscrita a través de procesos ideológicos, económicos, médicos, psicológicos... y cuya consecuencia más alarmante es el crecimiento del femicidio a nivel global. No debemos olvidar como las transformaciones económicas y sociales dejan a las mujeres y a los más vulnerables completamente desprotegidos.

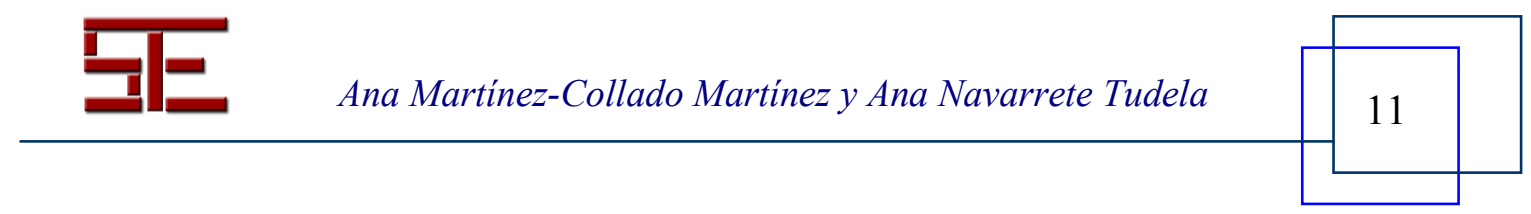




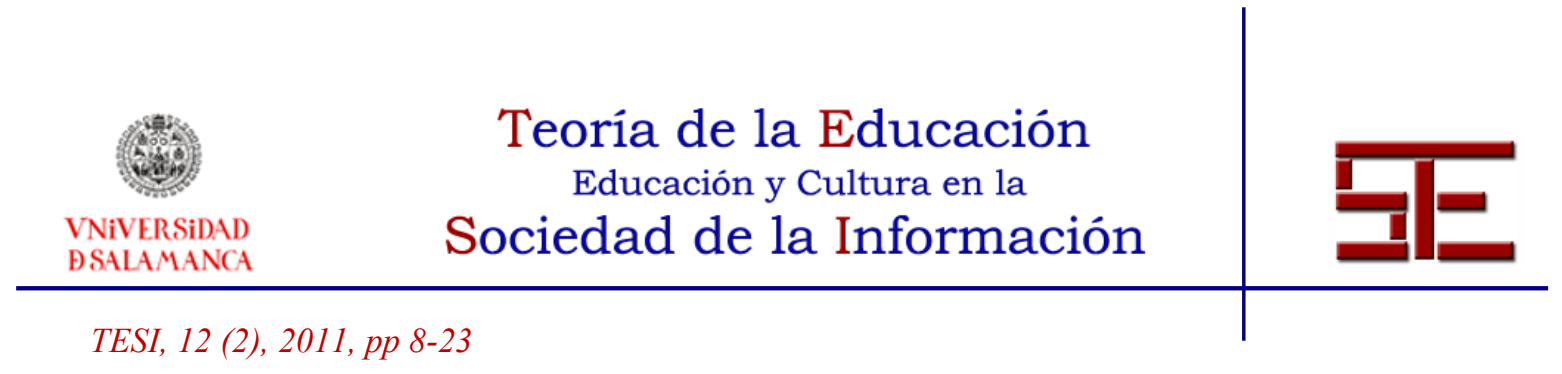

La involución se hace sentir en todos los ámbitos, toda apariencia de paridad es engañosa -hay miles de estudios publicados sobre la segregación por género en educación, el grado medio-bajo en la escala laboral al que acceden la mayoría de las mujeres, la imposibilidad de conciliación de la vida familiar y laboral o el techo de pobreza-.

Los años 90 fueron años de revisiones. Los 80 fueron años de conmociones, la estabilidad del orden económico se tambalea y desde mediados de los 80 empieza la recesión; a medida que la economía se expande las dificultades se acrecientan, con las graves consecuencias que supone para los sectores más vulnerables: restricción del empleo, contención de los salarios, flexibilización en las contrataciones; y de nuevo la recurrencia a la división sexual del trabajo o la exaltación de la maternidad.

La crisis se hizo sentir de igual modo en el campo de la representación. Las conquistas de la década de los 70 provocan a finales de los 80 una reacción airada contra el pluralismo, la diversidad, lo que produjo un fuerte rechazo hacia el trabajo artístico de las mujeres y las minorías y de nuevo se celebraron las figuras de autoridad ${ }^{3}$, se impuso un arte contemporáneo basado en las prácticas tradicionales y se respaldó con un orquestado notable éxito museístico y mercantil, a la vez que se rechaza el arte del performance y otras producciones englobadas bajo la terminología de "nuevos comportamientos artísticos", por efímeras y anticomerciales. En suma se impuso un arte mucho más adecuado al discurso neoconservador. El retorno de la pintura y la celebración de nuevo del héroe masculino artista tuvo en contrapartida la exclusión de las producciones hechas por mujeres en todas las grandes muestras. Recordemos los movimientos más representativos de la época: Supports/Surfaces, Bad Painting, NeoExpresionismo, New Image Painting, Pattern Painting, Figuración libre - Graffiti, NeoGeo, Trans-vanguardia.

La aguda crisis de la representación llevó a ciertos y ciertas artistas en los años 90 a cuestionarse el papel que la representación cumplía en la construcción de la realidad, y en la definición de las identidades de género; en este sentido se revisaron las prácticas artísticas de años 70 y fueron revitalizadas, sobre todo por su implicación en las cuestiones de identidad y asimismo en la preferencia por las prácticas no objetuales (antimercantilistas y poco interesantes para los museos): performance, vídeo y arte público. El performance y el vídeo eran los medios más radicales y los menos sospechosos para las prácticas feministas ya que no arrastraban el peso de la tradición masculina de otras prácticas como la pintura. Judy Chicago precisaba que la cólera

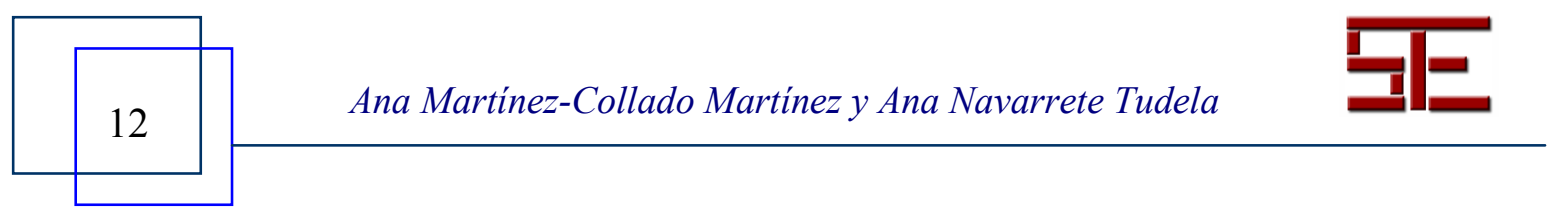




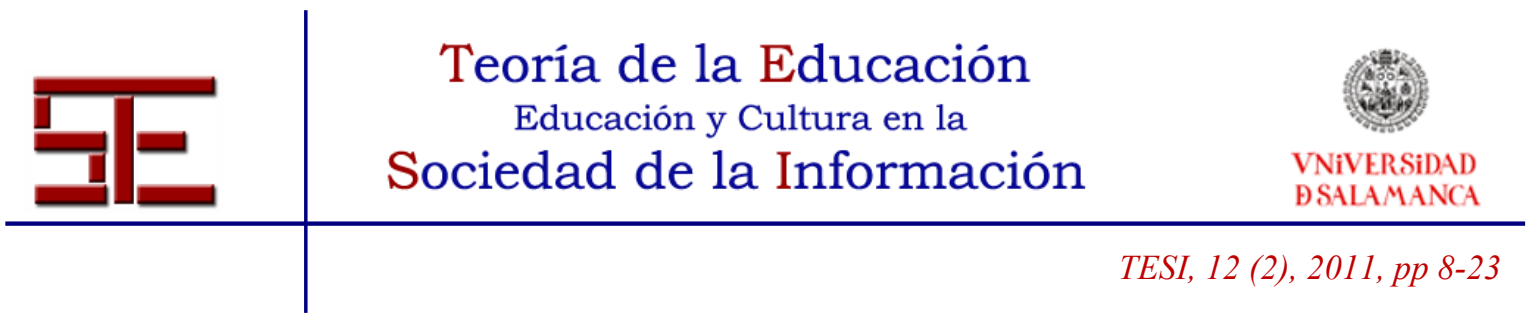

puede alimentar el performance con una intensidad que la pintura y la escultura no pueden conocer o Shigeko Kubota en 1976 con cierto radicalismo provocador afirmaba que el vídeo es la venganza de la vagina. Ambas sentencia explican muy bien el uso combativo de ambos medios, convertidos en un arma que permite reflexionar sobre dos de los asuntos que más han interesado al arte de las últimas décadas: el cuerpo y la identidad.

Tomar la cámara se ha hecho absolutamente necesario no sólo para dar voz a muchas mujeres, sino para visibilizar a las mujeres fuera de las construcciones genéricas, normativas y jerárquicas, y sobre todo porque las subjetividades emergentes necesitan otros modelos, nuevos modelos, hoy vivimos una época de crisis de todo tipo muy propicia para revisar las prácticas visuales y reflexionar de nuevo sobre el papel que cumple la representación en la construcción de lo real.

\section{PRÁCTICA ARTÍSTICA AUDIOVISUAL FEMINISTA EN LA DÉCADA DE LOS 70 Y 80: REINSCRIPCIONES DE DISCURSOS AUSENTES Y CRÍTICOS RESPECTO A LA REPRESENTACIÓN CULTURAL}

En el campo de la investigación feminista sobre el vídeo, Laura Cottingham promovió a finales de los años 90 varios proyectos muy significativos revisando las producciones artísticas de las artistas feministas: NowHere (1996) cruzaba artistas de los años 70 y 80 o Vraiment feminist et Art (1997) -que también revisaba este periodo-. Incluso Laura Cottingham realiza un vídeo-ensayo: Not For Sale: Feminism and Art in the U.S.A. during 1970's (1998), que se ha convertido en una herramienta fundamental para la enseñanza en universidades americanas.

En esta época los artistas en general encontraron en el soporte vídeo un vehículo perfecto para subvertir los discursos dominantes emitidos por los mass media y la cultura en general y armar una contra-información. Las artistas feministas pronto aprendieron su alcance, no sólo era un soporte nuevo ajeno al peso de la tradición patriarcal, sino además era un medio flexible. En los primeros 70 se pudieron ver muchos vídeos claramente feministas de corte documental, muy cerca del Cinema Verité y muy concienciados políticamente. Un trabajo videográfico que visibilizaba la dificultad de la vida de las mujeres en sociedad y sobre todo pretendía y buscaba ser un vehículo para la autoconciencia.

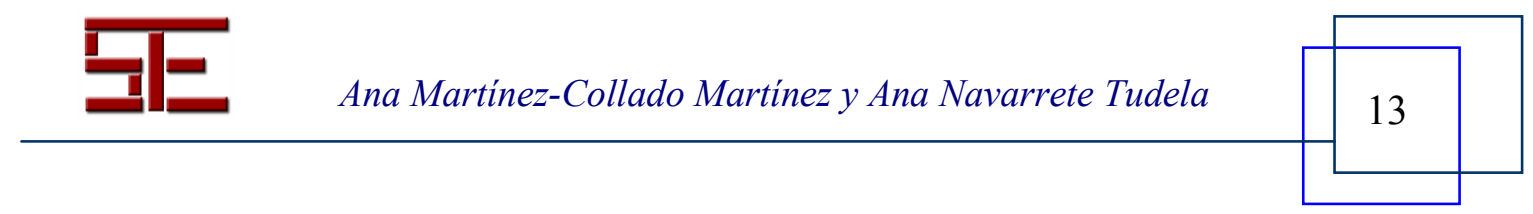




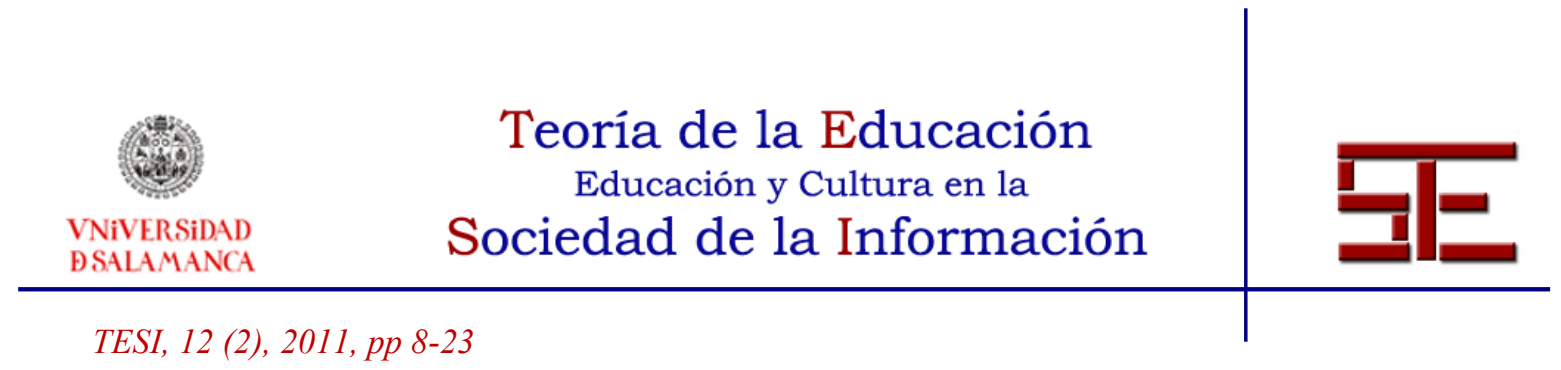

Las feministas de los 70 sabían que una de las más efectivas estrategias para eliminar los estereotipos de masculinidad y feminidad es transformar el orden simbólico. Pusieron en evidencia como la discriminación simbólica se perpetua entre otras cosas a través de las imágenes que construyen y reproducen lo social, y el papel que en este sentido cumplen los media, la cultura, el cine y otros productos de la industria cultural, en la perpetuación de las dominaciones de género, de raza y de clase.

Así la manipulación y tergiversación del discurso televisivo fue una táctica muy eficaz. En Tecnology/Transformation: Wonder Woman (1978) Dara Birnbaum nos muestra una imagen apropiada y manipulada y montada en un bucle sin fin de la famosa serie televisiva.

También se utilizó el vídeo como documento histórico. La performance feminista encontró un vehículo absolutamente esencial. Faith Wilding, en Waiting (1971), se sienta pasivamente con las manos sobre el regazo y mientras se balancea hacia delante y hacia atrás, va diciendo un listado de cosas por las que espera la mujer: “...esperando para que alguien me recoja, esperando usar sostén, esperando la menstruación, esperando que él me llame, esperando casarme, esperando la noche de bodas, esperando que él llegue a casa para llenar mi tiempo...”.

Muchas de estas artistas feministas del vídeo sabían que era esencial politizar la subjetividad.

Martha Rosler, en Vital statistics of a citizen, simply obtained (1977), nos presenta unas imágenes de objetualización del cuerpo femenino, del cuerpo vigilado científicamente, medido, controlado, un gran instrumento de regulación y control social sobre las mujeres. En él una voz de mujer nos repite: "Feminicidio Feminicidio Feminicidio Feminicidio Feminicidio. Crímenes contra las mujeres Ablación femenina Violación Ablación femenina Brutalidad forzada Pornografía Esterilización Maternidad forzada Ilegalización Aborto Ilegal Aborto Maltrato de Mujeres Acoso Insulto Odio Derogación Victimización Depredación Privación Femicidio Femicidio Femicidio Femicidio”.

El siglo XXI realizó nuevas revisiones e investigaciones feministas sobre las prácticas artísticas y culturales politizadas de los años 70, culminando algunas en proyectos expositivos: como en el MOMA; en el Museo de Arte de Brooklyn (primer Centro de Arte Feminista de Estados Unidos, el Elizabeth A. Sackler Center for Feminist Art), con exposiciones como Global Feminisms (2007) y Pharaoh, Queens and Goddesses

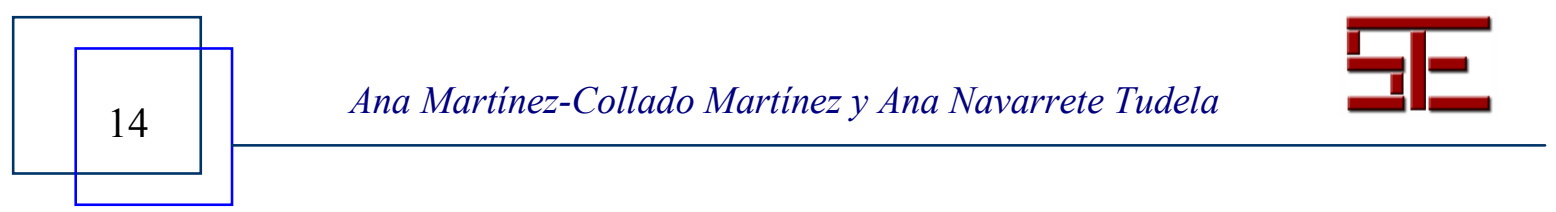




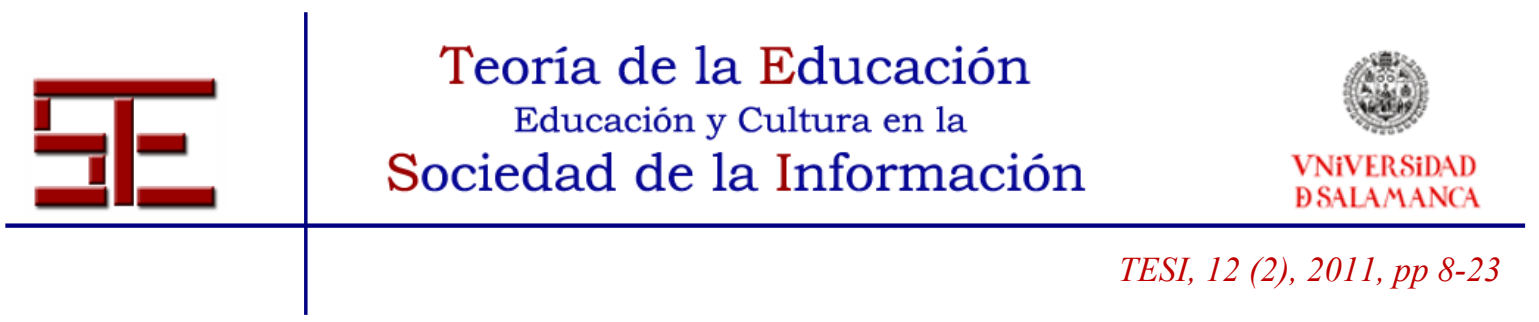

Faraonas (2007) ${ }^{4}$, y el Museo de Arte Contemporáneo de Los Ángeles, que se inauguró con la exposición WACK! Arte y Revolución Feminista (2007), que repasa el arte feminista del periodo 1965-1980. También han proliferado estas iniciativas en galerías, centros de arte y universidades, como en Nueva York, Nueva Jersey y California 5

La importancia de todos estos acontecimientos radica en el reconocimiento del legado del movimiento feminista en los últimos treinta años. Las iniciativas son en su mayoría lideradas por The Feminist Art Project ${ }^{6}$, una organización administrada por la Rutgers University de Nueva Jersey que actúa contra la marginación continua de las mujeres en la historia de la cultura.

Esto ha tenido un correlato en el territorio español con exposiciones como: Kiss Kiss Bang Bang. 45 años de arte y feminismo (2007), en el Museo de Bellas Artes de Bilbao; La batalla de los géneros (2007), en el CGAC de Santiago de Compostela, o Contraseñas. Representaciones femeninas en vídeo (2007), en el Centro Cultural Montehermoso de Vitoria.

Por un lado, el movimiento feminista ha ido perdiendo protagonismo en la esfera pública $\mathrm{y}$, sin embargo, hay constantes esfuerzos por conmemorar y revitalizar su legado en la actualidad y esto ocurre porque el movimiento de las mujeres sigue perjudicando seriamente al sistema.

\section{PRÁCTICAS ARTÍSTICAS AUDIOVISUAL FEMINISTA A PARTIR DE LA DÉCADA DE LOS 90: NUEVOS MODELOS NARRATIVOS VINCULADAS A NUEVAS SUBJETIVIDADES Y DESARROLLO DE LA PRODUCCIÓN EN EL "CAMPO EXPANDIDO"}

Pero aun así, a pesar de las dudas -tal vez más en un terreno social y vital-, ha sido un reto y una posibilidad, y es una evidencia el hecho de que las mujeres artistas se han lanzado a experimentar con las nuevas tecnologías. Griselda Pollock en "Historia y Política. ¿Puede la Historia del Arte sobrevivir al Feminismo?” (1994) ${ }^{7}$ señalaba el punto de fuga que iniciaron las artistas contemporáneas desde finales de los años setenta y principios de los ochenta aproximándose al trabajo de las nuevas tecnologías.

Muchas han tratado de resolver su práctica artística enfrentándose con la tradición existente, proponiendo nuevos temas y nuevos materiales artísticos. Las mujeres "artistas" tienen que establecer una relación con una práctica que históricamente las ha

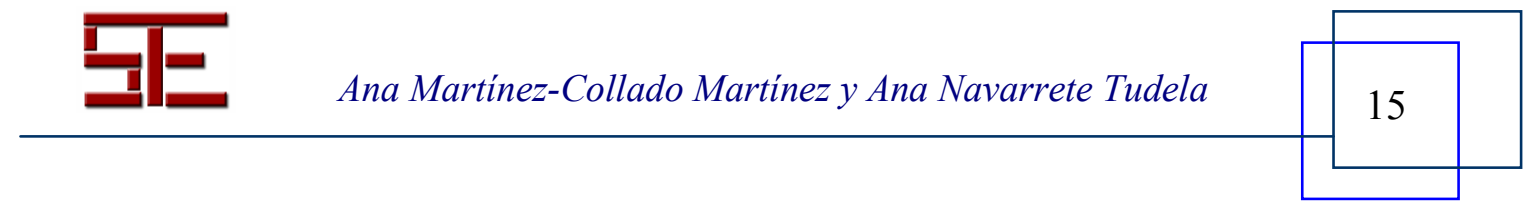




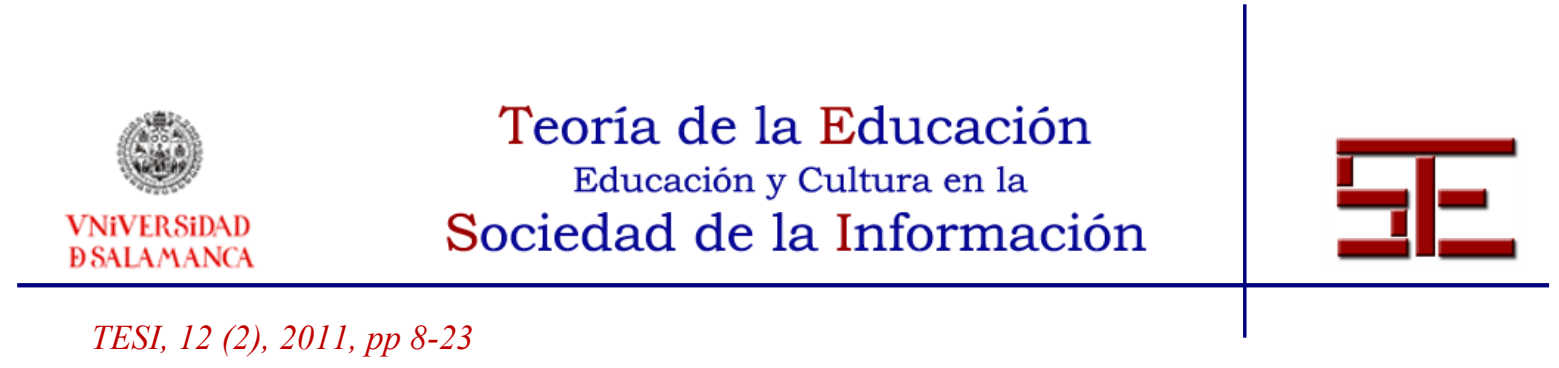

excluido, y cuyas categorías como genio, maestro, creatividad discriminan a las mujeres.

Es en relación con esta búsqueda $-\mathrm{y}$ a pesar de las polémicas y de los diferentes enfoques- en donde se sitúa la vocación de las mujeres por trabajar con los nuevos medios artísticos -desde la fotografía, el vídeo o Internet-. Asumir el compromiso de hacerse visible conducía a la utilización de otros medios donde los discursos creativos no estuvieran tan asociados a visiones masculinas del mundo. Es en el espacio de la innovación, de los discursos críticos, de la crítica y de la deconstrucción de los modelos tradicionales de representación, en los lugares más radicales de la experimentación donde el trabajo de las mujeres en el arte contemporáneo ha sido más excepcional.

Las mujeres se incorporan al espacio de las nuevas tecnologías y los nuevos medios para visibilizarse y para cumplir con el programa de desmantelamiento de aquellos patrones de la tradición artística que las habían relegado desde siempre. La nueva materialidad de la obra de arte, el nuevo tipo de relaciones con el espectador interactividad, la posibilidad de establecer una relación crítica abierta con los mass media y la sociedad de la información, son sin duda nuevos seductores territorios. Hacer un recorrido por las mujeres artistas más significativas durante los años ochenta y noventa del siglo anterior -Laurie Anderson, Martha Rosler, Mary Kelly, Lynn Hershman, Sophie Calle, Silvia Kolvbowsky, Dara Birnbaum, Mona Hatoum y las muy conocidas, Cindy Sherman, Louise Lawler, Jenny Holzer y Barbara Kruger, entre otras muchas, es una evidencia de estas posibilidades.

Las artistas mujeres que a finales del siglo pasado comenzaron a incorporarse con un cierto nivel de igualdad al mundo del arte institucional contemporáneo han elegido de forma mayoritaria las nuevas tecnologías, desde el vídeo, la fotografía, hasta los nuevos medios digitales. Es una evidencia, como sugiere Griselda Pollock, que la pintura por su tradición como arte del genio no dejaba mucho espacio a las nuevas "maestras". Pero también hay que destacar que el mundo digital no es ya una alternativa, es la realidad diaria, accesible -al menos en el primer mundo- a cualquiera. El matiz, la diferencia, tal vez esté en que los procesos digitales favorecen la investigación en la representación de la identidad -de la deconstruida subjetividad contemporánea- con innovadores resultados. Y las artistas mujeres han hecho una apuesta fuerte: repensar la identidad, repensarla desde su experiencia como mujeres a través de los nuevos medios digitales.

Ciertamente, los múltiples significados de "ser feminista" dependen de nuestro contexto social y político. Pero defendamos también una noción de la diferencia -herencia del postestructuralismo

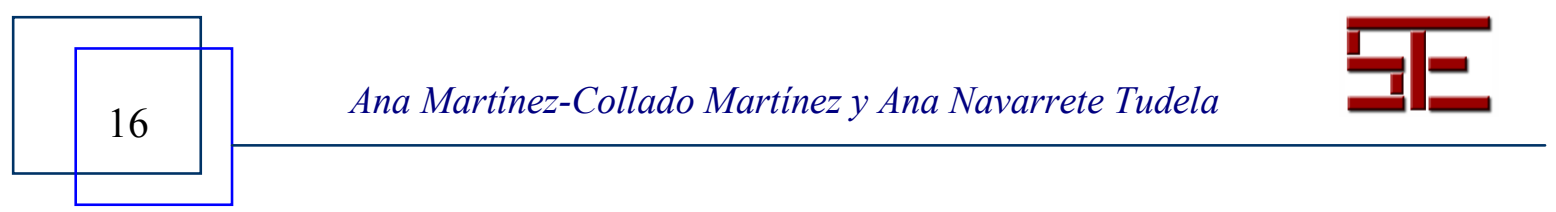




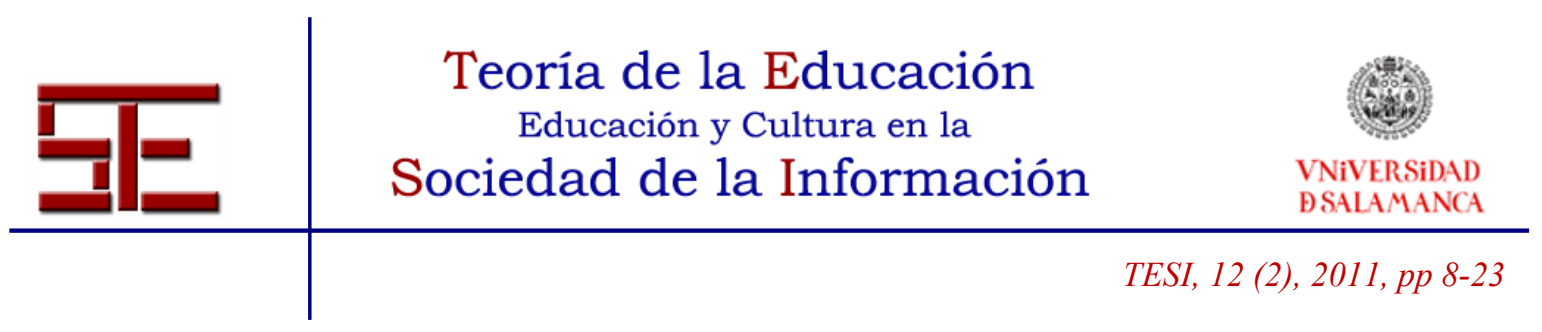

y del psicoanálisis-, que desde los años setenta ha aportado conceptos imprescindibles para abordar la representación de género -de toda subjetividad-, que pasaría por nociones como deconstrucción, crítica a la representación, la redefinición de los patrones del deseo como impulso transformador, la subjetividad "nómada", la constitución performativa del género, la hibridación, el mestizaje, o la construcción cyborg de la identidad contemporánea. "Estos conceptos no atienden a limitaciones ni a fronteras. El feminismo, como todo el programa moderno, se ha sometido a un intenso proceso autocrítico, alejándose de cualquier dogmatismo y abriéndose a una multiplicidad de narrativas (Martínez-Collado, 2008, 5).

Un nuevo modelo narrativo vinculado a la experiencia de la subjetividad contemporánea. Rosi Braidotti, a propósito de las nuevas prácticas del discurso feminista, defendía un modelo de subjetividad plural, entendido como el desarrollo de "un nuevo nomadismo". Una noción de identidad múltiple y plural que se construye ficcionalmente, a partir de estrategias narrativas y existenciales. Multiplicidad de significados y formas de darse la identidad que coinciden con la imposibilidad de la visión unidireccional del mundo, que forma parte de la conciencia que sabe de la inutilidad de las manifestaciones de certidumbres inequívocas.

Esta pluralidad de enfoques se desarrolló a partir de los años 90 a partir del desarrollo de múltiples narratividades vinculadas a las experiencia de la mujer y también a lo que podríamos llamar la "expansión del campo de producción" en relación a la utilización del vídeo y la performance.

Sin tratar de hacer un recorrido por la pluralidad de los discursos y narraciones cita, en que se desarrolla la participación de las mujeres en el territorio expandido de las nuevas tecnologías, las temáticas principales irían desde las más variadas perspectivas en torno a la identidad, las relaciones cruzadas entre el género y la nueva sociedad tecnológica y, finalmente, aquellos que incorporan la perspectiva de la globalización y la confrontación intercultural.

La utilización por parte de las prácticas artísticas de distintos medios -fotografía, cine, vídeo, Internet- y la manipulación de imágenes nos permite hablar de la producción de Interfaz -como metáfora de un espacio de producción ideológica y de contenidos-, entendida como un cambio en su puesta en escena.

A pesar de estar inmersas y confundidas en el imaginario visual del espectáculo global, mantienen el privilegio de la distancia y, por lo tanto, de una cierta capacidad crítica. Como nuevo espacio de producción, ofrecen una cantidad de posibilidades creativas, de experimentación y de innovación formal. "En cierta forma, el concepto de "campo

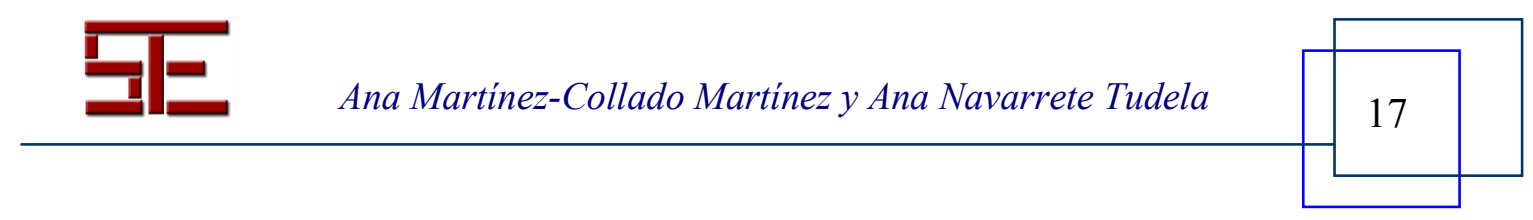




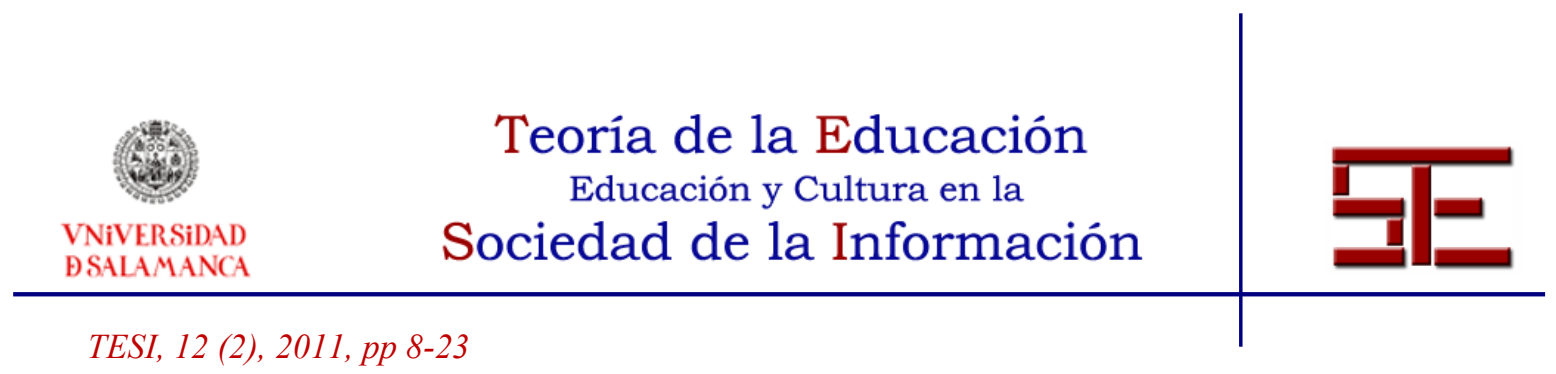

expandido" propuesto por Rosalind Krauss en referencia a la escultura y la instalación de finales del siglo XX, se ve reforzado y cumplido. Al tiempo, la estructura híbrida del Interfaz favorece la posibilidad de desarrollar propuestas comprometidas, connotadas políticamente" (Martínez-Collado, 2008, 97).

En este sentido, la exposición Cyberfem. Feminismos en el escenario electrónico ${ }^{8}$ producida por el Espai d'Art Contemporani de Castelló en 2006-2007, fue un ejemplo de la intención que deseaba recoger la evolución dinámica de las propuestas artísticas de los distintos "feminismos" realizadas a través de las nuevas tecnologías digitales.

\section{PRÁCTICAS AUdiovisuALES FRENTE A LA GLOBALIZACIÓN Y LA SOCIEDAD DE LA INFORMACIÓN}

Uno de los territorios por los que se han desarrollado las prácticas feministas audiovisuales ha sido el que analiza las problemáticas de la globalización. En general el carácter autobiográfico del arte contemporáneo actual aproxima su discurso al discurso postcolonial - intercultural, en tanto que cada vez son entendidos desde su complejidad local. De tal forma que la memoria y el recuerdo de la experiencia visibiliza a través del espacio doméstico los problemas de la diferencia, la identidad, la raza y la etnicidad.

Es relevante, por lo tanto, y cada vez más tener en cuenta la relación entre el arte feminista actual y el discurso de las minorías. Este feminismo expandido que se inicia en los 90 ha ocupado también un espacio importante en el debate de "la diferencia cultural" -de la relación con el "otro" cultural-. Ello es fruto, por una parte, del reconocimiento actual del trabajo de las mujeres, pero, por otra, es signo de la coincidencia de preocupaciones, respecto a la tematización de las problemáticas del cuerpo y la identidad del arte hecho por mujeres. Las distintas tendencias del feminismo se han hecho conscientes de que parámetros como clase, raza o hábitos sexuales son también fundamentales. Ya no priorizan el analizar los problemas de alguna universal "clase-mujer", sino el reconocer que sus circunstancias son concomitantes con las problemáticas de otras minorías.

No se proponen en ningún caso sumar las fuerzas de los excluidos -ni el ser mujer, ni el ser negro, ni el ser homosexual deben constituirse en "excepciones"-, sino que se trata más bien de exigir otras formas de representarse la realidad. Lucy Lippard, una de las críticas de más reconocido prestigio desde los años 60, escribió a principios de los 90 sobre el arte de las minorías en América. En Mixed Blessings. New Art in Multicultural

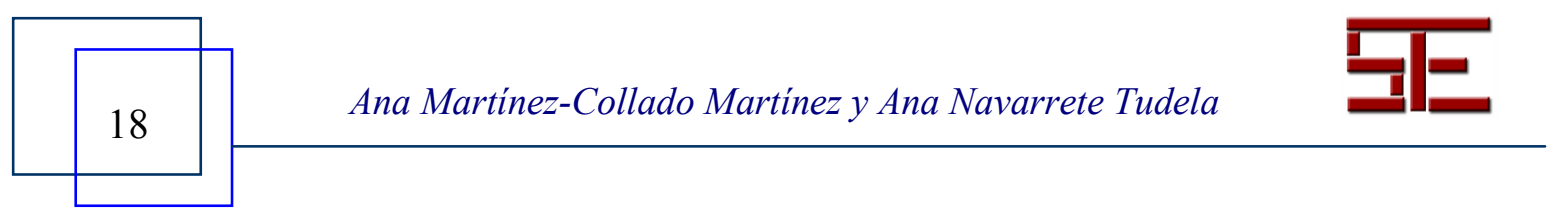




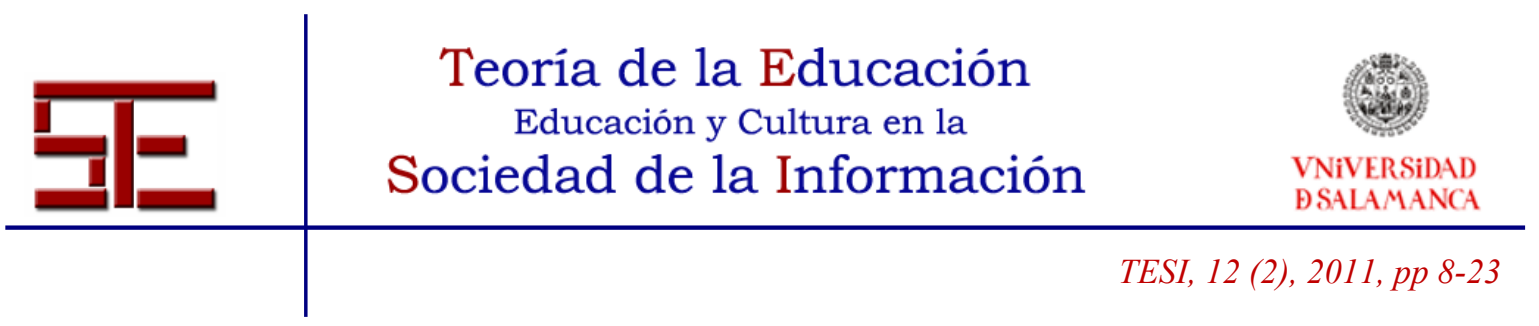

America plantea la posibilidad de un modo alternativo de representarse la realidad definido en términos de diálogo. El trabajo de los - las nuevos artistas acaba por poner de manifiesto la imposibilidad del discurso dominante para enfrentarse a las diferencias sin intentar reducirlas, hacerlas propias. Esta circunstancia señala también otro punto de contacto entre el discurso feminista y el multicultural: ambos son las nuevas víctimas de la institucionalización del discurso multicultural, en un momento en que el arte de las minorías ha comenzado a ser reconocido y casi se ha convertido en la nueva tendencia dominante, en el nuevo canon. El gran problema es cómo expresar esta diferencia sin consentir su domesticación, su subsunción en un nuevo desarrollo de la cultura occidental dominante, sin consentir que ese proceso la haga desaparecer, convertida en una moda banalizada, y convertido el tema de la diferencia y las minorías en un producto más del mercado "políticamente correcto".

Como sucedía respecto al género y al sexo-, la cada vez más abundante visualización performativa de las imágenes de otras razas o culturas hechas por mujeres artistas como Lorna Simpson, Marlene Dumas, Mona Hatoum, Shirin Neshat, Fiona Tan, y Tiong Ang, por ejemplo- nos hace explícita la situación de interculturalidad del mundo contemporáneo. Trabajos que ocupan un espacio importante en el debate de la diferencia cultural, de la relación con el otro.

El concepto de frontera ha adquirido en muchas ocasiones un carácter dramático Lourdes Portillo, Mujeres extraviadas - Missing Young Woman (2001). Si la complejidad de la representación o visualización de la diferencia está antropológicamente basada en el odio y el temor a la diferencia, su violencia se refuerza al añadirse factores económicos y de desigualdad social.

Ursula Biemann puede ser hoy el modelo de esta producción de imágenes. Sus proyectos coleccionan, recoleccionan y presentan a través de narraciones fracturadas imágenes e información de un mundo percibido como una base de datos "transdisciplinar". Sus video-ensayos vídeo conectan el discurso macro con lo micro en el terreno de las prácticas políticas y culturales.

Las distintas fronteras y los conflictos que suponen para la violencia contra las mujeres son sus temas preferentes. Todos recordamos Performing the Border (1999), un vídeo centrado en las fronteras de México - EE.UU. Concretamente en la Ciudad Juárez, donde se localizan las industrias maquiladoras de propiedad estadounidense. El vídeo trata sobre la sexualidad de la región fronteriza, el trabajo en la maquila, la prostitución,

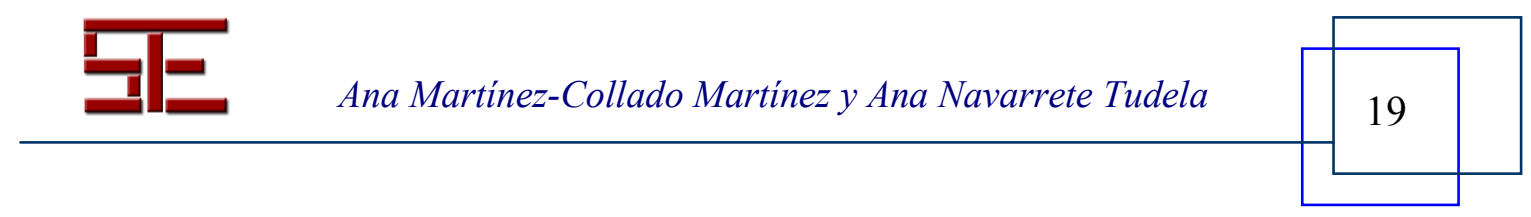




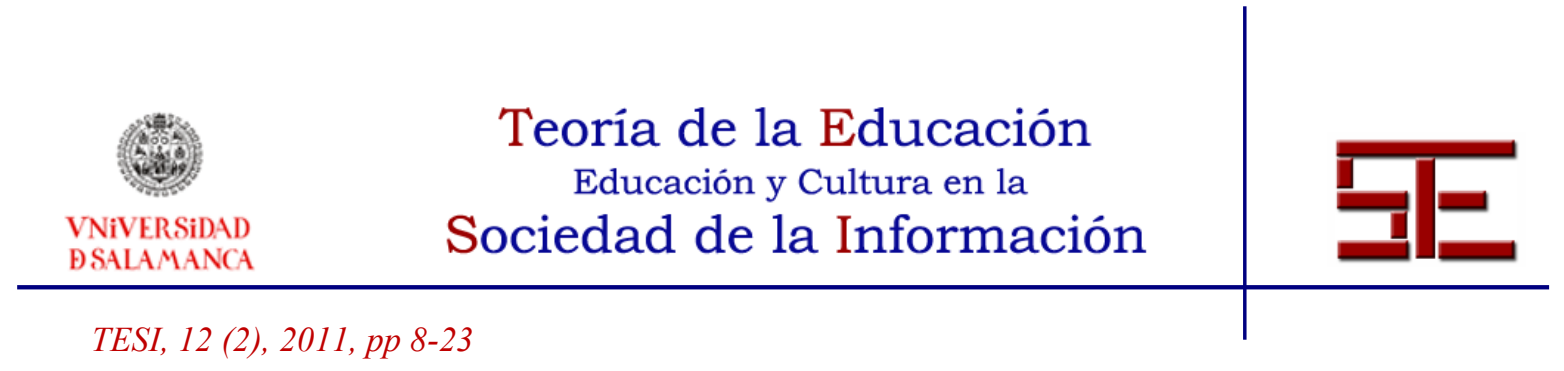

la expresión de los deseos de la mujer en la industria del ocio y la violencia sexual en el ámbito público.

Remote Sensing (2001) es otro vídeo-ensayo en el que las imágenes nos trasladan a los territorios del comercio mundial del sexo desde la Europa del Este al este de Asia. En el vídeo explora la vida de las trabajadoras sexuales y sus "datos personales" a través de imágenes de satélite. Pretende transmitirnos lo que significa sentir el mundo de forma remota a través de los gráficos que rodean a la tecnología de los medios utilizados para rastrear, vigilar, desde la distancia.

Tendríamos también que hacer mención del proyecto Videoletters las mujeres: un segundo texto sobre la guerra y la globalización (2001). Una compilación de videocartas que surgió de la invitación a participar a mujeres de todo el mundo, con un pequeño corto a modo de videoletter sobre la guerra y la globalización con la intención de reunir diferentes perspectivas en relación con las jerarquías sociales, la militarización, la guerra y sus consecuencias. Y a la vez, demostrar la conexión mundial entre la pobreza sostenida, las jerarquías de género y la heterosexualidad normativa mediante la recopilación de las diferentes perspectivas regionales.

El proyecto se inició durante la guerra en Afganistán. Surgió en una reunión sobre vídeo-activismo en Berlín en octubre de 2001, donde había alrededor de diez mujeres vinculadas al medio, procedentes de la India, Alemania, México y Suiza. Sintieron la necesidad de reaccionar a la nueva situación global de militarización del mundo generada después del 11 de septiembre del 2001.

En 2002 se distribuyó la primera edición de Videoletters producida por mujeres activistas y cineastas de la India, México, Alemania, EE.UU. y Francia. Esta primera compilación se muestra en manifestaciones, acontecimientos políticos, seminarios universitarios y festivales de cine y vídeo, constituyéndose en una herramienta muy útil para el intercambio de perspectivas críticas feministas de las mujeres de diferentes contextos.

Es muy significativo como muchas organizaciones de mujeres a nivel global se apropian de tecnologías de comunicación -por ejemplo, las utilizan para realizar talleres audiovisuales donde se anima a las participantes a tomar la cámara-. Estas iniciativas son una solución para transmitir información y conocimiento. Su eficacia en diversas áreas -defensa de los derechos de los Pueblos Indígenas, defensa de los derechos

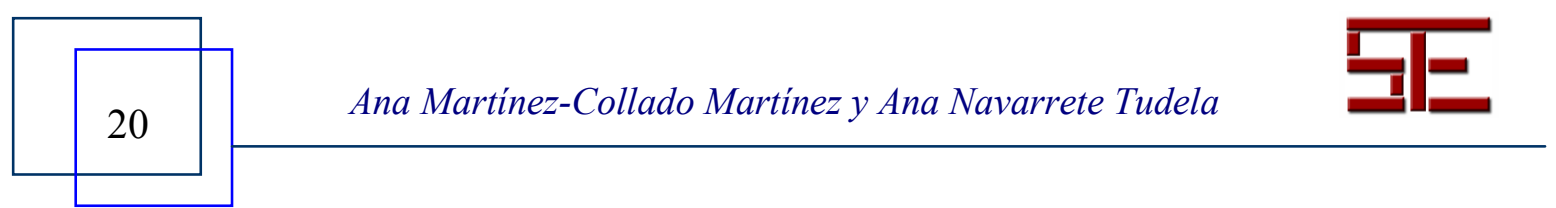




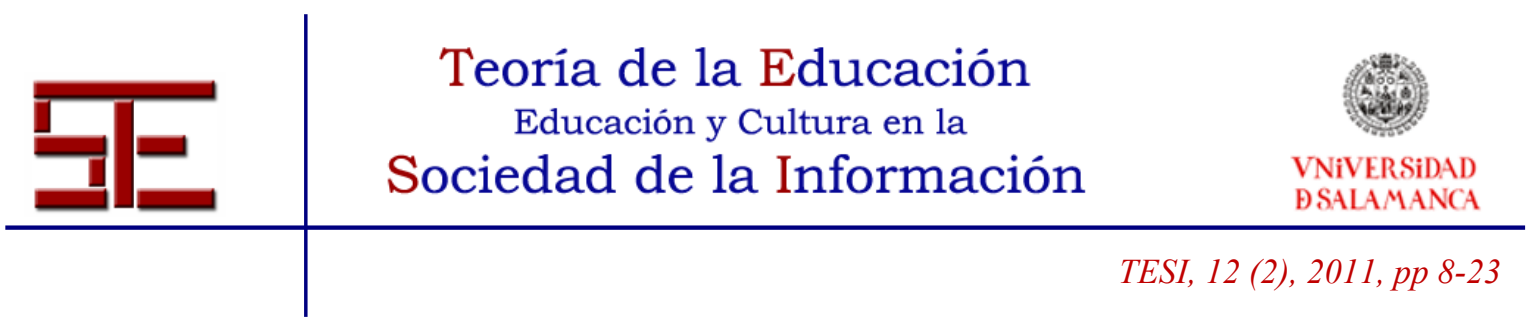

sexuales y los derechos reproductivos, el trabajo, la prevención del VIH, la salud sexual y la salud reproductiva, el desarrollo rural y los problemas medioambientales (cambio climático o calentamiento global) demuestra la enorme incidencia política del activismo de las mujeres con la cámara y en la producción de contra-información.

El objetivo es fortalecer las capacidades de estas organizaciones para que puedan generar sus propios guiones y comunicar sus campañas o mensajes. Desde finales de los años 90 Internet deviene el vehículo primordial para hacer públicos estos materiales audiovisuales y aunque sabemos que el $66 \%$ de la población del mundo no ha accedido aún al teléfono, como afirma T.V. Maxabomba ${ }^{9}$, su difusión depende no tanto del desarrollo económico del país sino de la creatividad de sus propuestas y producciones.

Otro trabajo de instalación concebido a modo de interfaz multimedia y proyecto audiovisual, $N$-340. Globalfem (2006), de Ana Navarrete nos visibiliza los cruces entre políticas locales y globales en relación a las mujeres emigrantes en el contexto de Castelló (España). El proyecto $N-340$ articula, a través de varios dispositivos tecnológicos y críticos on-line y off-line, este conjunto de problemáticas atendiendo a la situación de desprotección social y laboral de la mayoría de las mujeres inmigrantes. "La N-340 -como propone Ana Navarrete- es un lugar de tránsito masivo de mercancías y cuerpos. Esta carretera permite visibilizar y entender cómo los cuerpos de las mujeres son una mercancía que produce altos beneficios, jugando un papel importante en la producción y reproducción del capitalismo globalizado" (Navarrete, 2007).

En la sociedad y en la institución arte - tanto en occidente como en otros lugares todavía lejanos para nosotros-, por supuesto, queda mucho por hacer. La discriminación sigue siendo abrumadora.

Los primeros pasos están siendo dados. Las mujeres artistas y teóricas actuales son capaces de transmitir en su discurso una experiencia de la diferencia. No una representación esencialista de un "ser mujer", pero sí una representación, una narración de aquellas experiencias sobre el mundo que les rodea en la que se refleja otra visión de la historia, de nuestra historia común. Las prácticas feministas desarrolladas a través de los nuevos medios de la sociedad de la información están visualizando el complejo marco de posiciones y de vertiginosos cambios identitarios, sociales y políticos en relación a la cuestión de género. Críticamente comprometidos con la realidad que nos rodea nos aproximan a la dificultad de la experiencia, tanto en el espacio privado como en el público, de las "mujeres" -de toda construcción de la subjetividad contemporánea-.

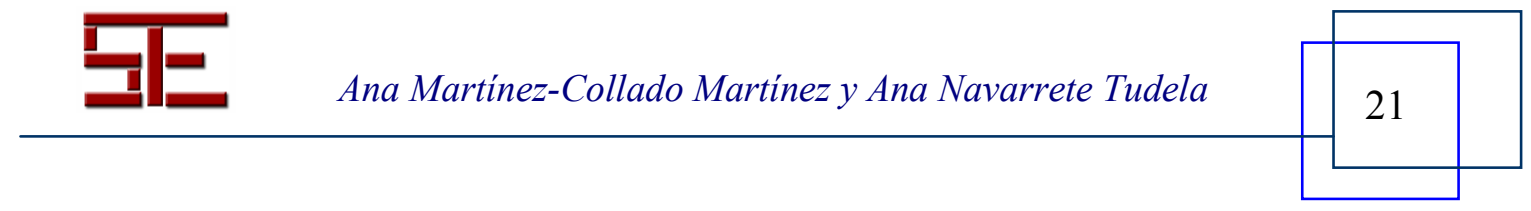




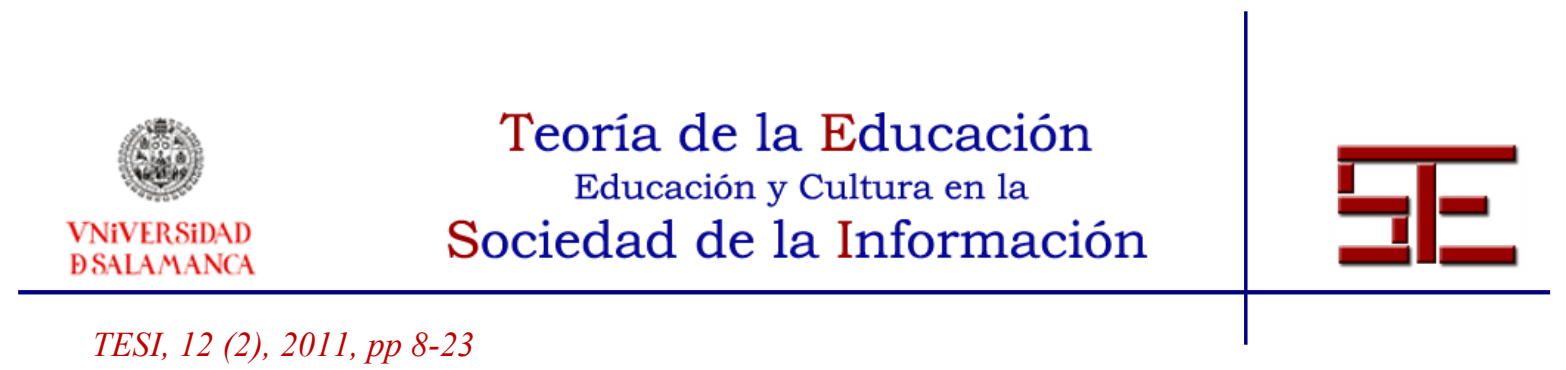

\section{BIBLIOGRAFÍA}

Apple, M. W. \& Beane, J. A. (1997). Escuelas democráticas. Madrid: Morata.

Bourdieu, P. (1994). Razones prácticas. Sobre la teoría de la acción. Barcelona: Anagrama.

Braidotti, R. (1994). Sujetos nómades. Barcelona: Paidós.

Butler, J. (1990). El género en disputa El feminismo y la subversión de la identidad. Barcelona, Paidós.

Faludi, S. (1991). Reacción. La guerra no declarada contra la mujer moderna. Barcelona: Anagrama.

García Canclini, N. (2004). Diferentes, desiguales y desconectados. Mapas de la interculturalidad. Barcelona: Gedisa.

Lippard, L. (1990). Mixed Blessings. New Art in Multicultural America. Nueva York: Pantheon Books.

Martínez-Collado, A. (2005). Tendenci@s. Perspectivas feministas del arte actual. Murcia: Cendeac.

- (2007). Cyberfem. Feminismos en el escenario electrónico. EACC de Castelló. http://www. cyberfem.net.

- (2008). Narraciones / visibilizaciones de la diferencia en la cultura de la Interfaz. En Estética: Perspectivas contemporáneas. Salamanca: Universidad de Salamanca.

Mirzoeff, N. (1999). Una introducción a la cultura visual. Barcelona: Paidós.

Mulvey, L. (1975). Placer visual y cine narrativo. Documentos de trabajo, Valencia: Fundación Instituto Shakespeare/Instituto de Cine y RTV.

Navarrete, N. (2007). N-340 (2006). http://www.n340.org/.

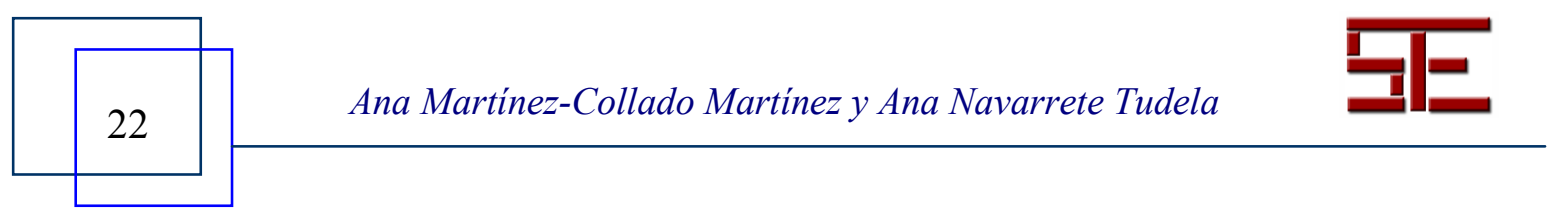




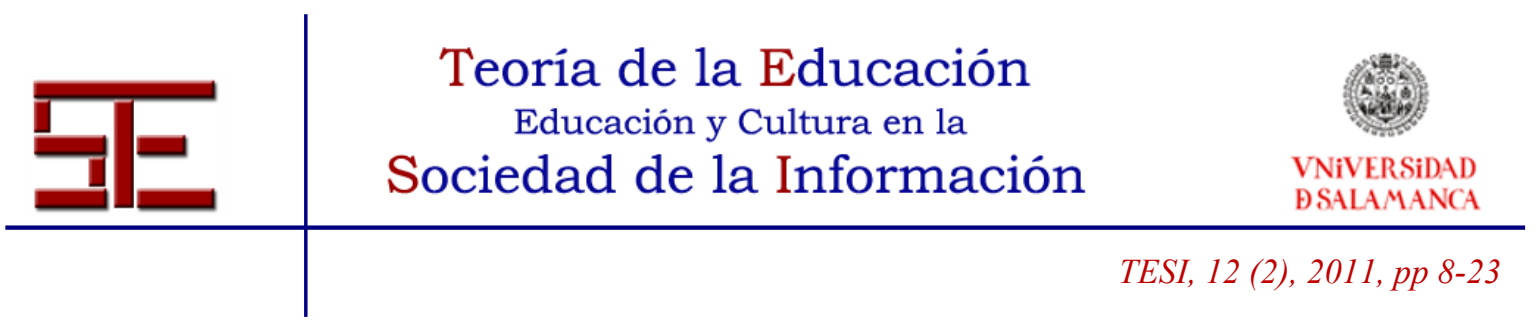

Pollock, G. (1994). Histoire et politique: ¿l'histoire de l'art peut-elle survivre au féminisme? En Michaud Y. (Ed), Feminisme, art et histoire de l'art. Paris: École Nationale Supérieure des Beaux-arts, Espaces de l'art. Traducido en: http://estudiosonline.net.

Vergne, Ph. (1996). L'art au corps: le corps exposé de Man Ray à nos tours. Marseille: Galeries Contemporaines des Musées de Marseille.

Wallis, B. (1984). Qué falla en esta imagen: una introducción. En Wallis B. (Ed.), Arte después de la modernidad. Nuevos planteamientos en torno a la representación. Madrid: Akal.

\section{NOTAS}

${ }^{1}$ Este artículo es uno de los más influyentes de la teoría y crítica fílmica feminista.

${ }^{2}$ En esta década de los 70 en el contexto europeo y americano, se produce el cine más interesante de la militancia feminista, películas como India Song (Francia, 1974) de Marguerite Duras, Jeanne Dielman, 23 Quai du Commerce, 1080, Bruxelles (Bélgica, 1975) de Chantal Akerman, Born in flames (EEUU, 1983) de Lizzie Borden, Lives of performers y Film about woman who... (197”) de Yvonne Rainer.

${ }^{3}$ Concepto desarrollado por Benjamín H.D. Buchloh en Figuras de autoridad, claves de la regresión. En Wallis B. (ed.), Arte después de la modernidad. Nuevos planteamientos en torno a la representación. Madrid: Akal, 2001.

${ }^{4} \mathrm{http} / / /$ www.brooklynmuseum.org/exhibitions/pharaohs_queens_goddesses/

5 Otras exhibiciones de estos años: Cómo las artistas mujeres estadounidenses inventaron el Posmodernismo: 1970-1975, en el Hunterdon Museum de Nueva Jersey y De adentro hacia afuera: Arte Feminista Entonces y Ahora, en la Saint John's University de Nueva York. También destaca la muestra Role Play: Revisión del Arte Feminista, que presentará la neoyorquina Galeria Lelong e incluye a artistas clave en el movimiento, como la cubana Ana Mendieta y la brasileña Anna Maria Maiolino. Las galerías de arte también están reabriendo sus puertas al arte feminista, entre éstas Cynthia Broan Gallery con la muestra What $F$ Word?, que reúne a mujeres de varias generaciones cuyas obras están relacionadas con palabras que comienzan con "F". Las feministas Susan Bee y Mira Schor, por su parte, han editado un número especial de su revista virtual MEANING, titulado "Arte Feminista: Una revaloración", en el que han contribuido artistas e historiadores de tres generaciones diferentes.

${ }^{6} \mathrm{https}: / /$ feministartproject.rutgers.edu/

${ }^{7} \mathrm{http}: / /$ www.estudiosonline.net/texts/pollock.htm

${ }^{8}$ Cyberfem. Feminismos en el escenario electrónico (2006 / 2007), Ana Martínez-Collado, EACC de Castelló http://www. cyberfem.net

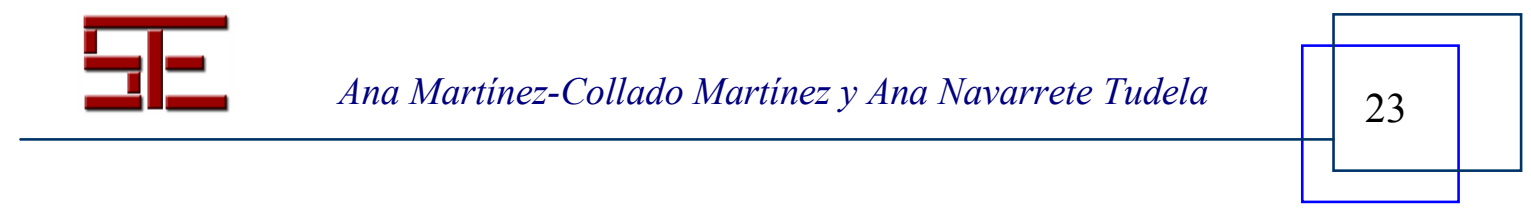


Teoría de la Educación

Educación y Cultura en la

VNiVERSIDAD

DSALAMANCA

Sociedad de la Información

TESI, 12 (2), 2011, pp 8-23

Para citar el presente artículo puede utilizar la siguiente referencia:

Martínez-Collado Martínez, A. y Navarrete Tudela, A. (2011). Mujeres e (industria) audiovisual hoy: involución, experimentación y nuevos modelos narrativos, en Barrios Vicente, I. M. (Coord.) Mujeres y la sociedad de la Información. Revista Teoría de la Educación: Educación y Cultura en la Sociedad de la Información. Vol. 12, no 2. Universidad de Salamanca, pp. 8-23 [Fecha de consulta: dd/mm/aaaa].

http://campus.usal.es/ revistas_trabajo/index.php/revistatesi/article/view/8271/8275 